\title{
90. Electron-Microscopic Findings of Placentae of Pregnancy Toxemia, especially, their Chorionic Epithelium
}

\author{
By Katsuji Kushima and Kiyoshi AneHA \\ Department of Obstetrics and Gynecology, Tohoku University \\ School of Medicine, Sendai \\ (Comm. by T. KumagaI, M.J.A., June 13, 1960)
}

There are many and various theories about the pathogenesis of pregnancy toxemia, but the problem has not been decidedly solved till now. It is true that the placenta takes an important position in pregnancy toxemia. Therefore, many works on the histochemical findings of placentae of pregnancy toxemia were done by Schmorl, ${ }^{1)}$ Tenney and Parker, ${ }^{2)}$ Stroganova, ${ }^{3)}$ Watanabe, ${ }^{4)}$ Namiki, ${ }^{5)}$ and so on. No difference was observed between placentae from toxemic patients and from normal women, when optic microscopy was used. Electron microscopy was first used by Takeyama ${ }^{6)}$ in order to study toxemic placentae. No such a report on placenta was yet known, but he could not find any difference between toxemic and normal placentae.

Accordingly, we studied with an electron microscope on the findings of the placenta from toxemic patients and found some differences between the ultrastructure of placentae of toxemic and that of nontoxemic patients. In this paper, we report on the findings of the chorionic epithelium with acute (or pure) and mixed (or complicated) pregnancy toxemia as compared with normal chorionic epithelium.

Materials and methods. Specimens of placentae sampled from women with toxemia of pregnancy immediately after delivery in the 10th month of pregnancy were fixed for 1 hour in 1 per cent osmium tetroxide solution buffered to $\mathrm{pH}$ 7.4, washed in distilled water, dehydrated with increasing concentrations of alcohol, imbedded in a $7: 3$ mixture of $n$-butyl and methyl methacrylate polymerized with benzoyl peroxide at $58^{\circ} \mathrm{C}$, sectioned with glass knives in a JUM-5 ultra-microtome (Japan Electron Optics Laboratory Co.) and examined under an HU-10 electron microscope (Hitachi Ltd.). Specimens of placentae from normal gravidae after full term parturition were treated in just the same way and mainly the cells of the chorionic epithelium of these two kinds of specimens were comparatively studied (Plate 1).

Observations. The results obtained were in summary as follows: (Plate 2)

1. Placentae of subjects with acute toxemia of pregnancy

The microvilli on the free surface of the chorionic epithelium were found reduced in length and relatively enlarged in diameter in 


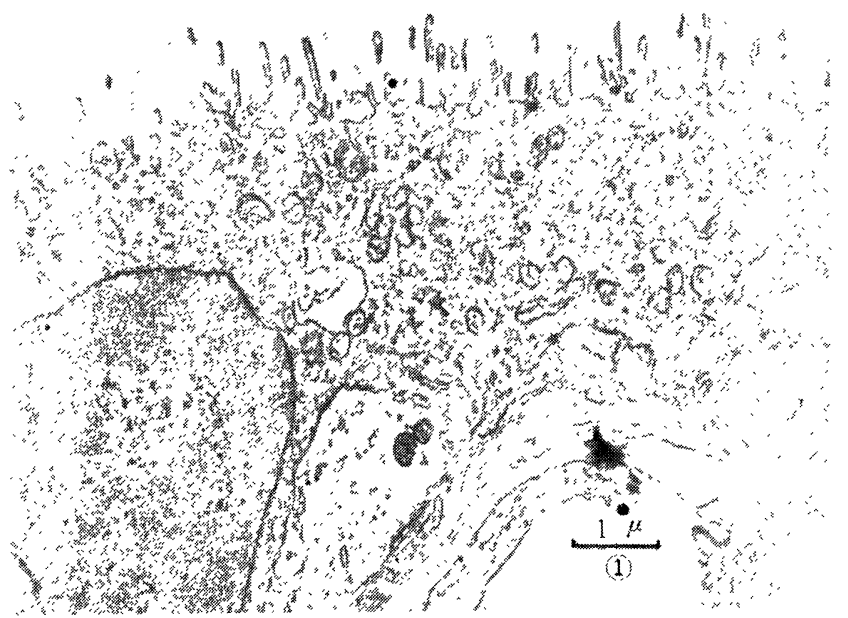

Plate 1. A chorionic epithelium cell in a placenta from normal gravida of 10 months of pregnancy

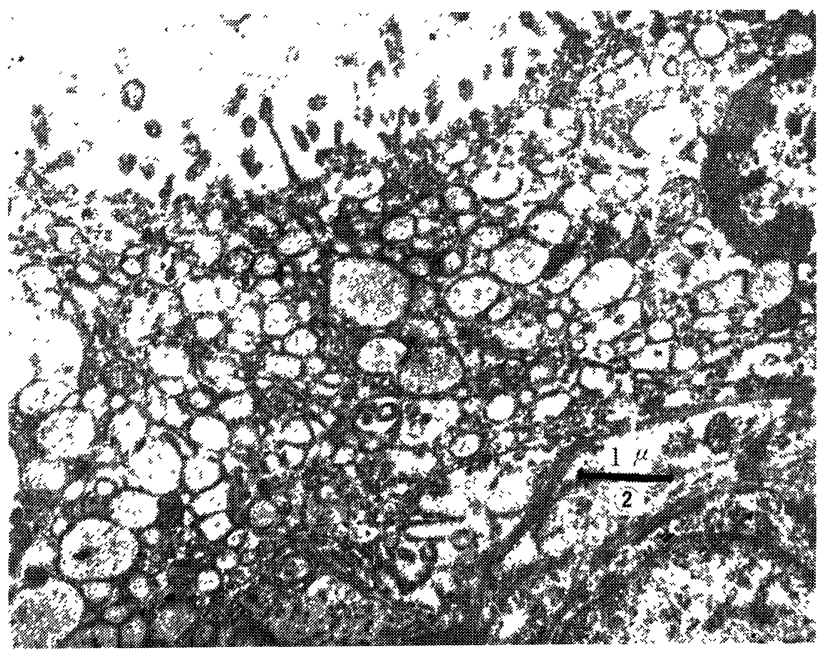

Plate 2. Chorionic epithelium of a placenta of a 28 year-old woman without past experience of pregnancy with toxemia edema, $(+)$; blood pressure, 138-114; albuminuria, $(+++)$; eclampsia; received cesarean section

comparison with the microvilli of normal mature placentae. As the most perceptible change in the cytoplasm, the appearance of many vacuole-like body in it may be mentioned. These bodies are large and generally round in form, have a wall of a single membrane and have Palade granules adhering on their outside, so that it is clear that these bodies are swollen rough-surfaced endoplasmic reticulum. ${ }^{8)-10}$ ) This endoplasmic reticulum grows the larger, the nearer this endoplasmic reticulum approaches the nucleus of the cell. Mitochondrias of the chotionic epithelium were only slightly swollen and the cristae 
occasionally broken, and slight degranulation and coarsening were observed in the nucleoplasm. Little change was found in the basal membrane.

2. Placentae of subjects with mixed toxemia of pregnancy (Plate 3)

In these specimens, the shortening of the microvilli was further advanced than in the acute toxemia. Some areas of the microvilli of the mixed toxemia showed the appearance of being smooth and even. The vacuolation was also more intensified, several vacuoles being frequently fused together and deforming the spherical outline. The tendency of the vacuoles to gain in size prevails here too, as the deeper parts of the epithelium are approached. In some areas, the very microvilli are seen vacuolated. The grade of the changes in the nuclei, the mitochondria, the basal membrane, etc. was not much different from that in the preceding observations.

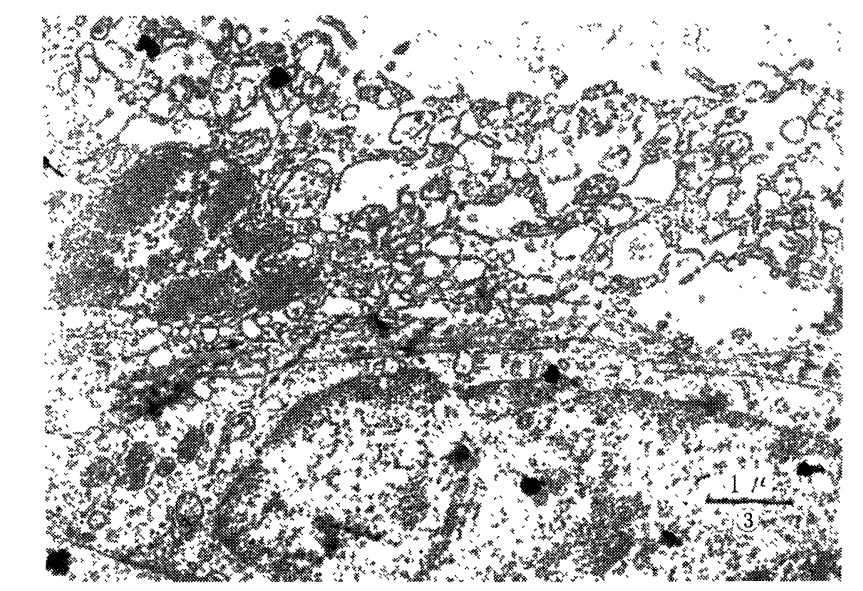

Plate 3. Chorionic epithelium from 35 years bipara with experience of 6 past pregnancies with mixed toxemia edema, $(+++)$; blood pressure, 152-86; albuminuria, $(++)$ Anamnesis: Toxemia, eclampsia, and cesarean section at 29 years and toxemia again at 31 years

Discussion. Concerning the swelling of the endoplasmic reticulum, Takeyama ${ }^{6}$ says that such a swelling is a process of stripping of syncytial epithelium, but this meaning is obscure. Takagi ${ }^{11)}$ says that these cells are vacuolated when immersed in hypotonic solutions but not when immersed in hypertonic solutions, and Sjöstrand ${ }^{12)}$ says that such swelling comes forth only when the blood-flow is disturbed.

Summary. We observed the chorionic epithelium with acute (pure) and mixed pregnancy toxemia using an electron microscope. The results were as follows:

1. The microvilli of syncytial epithelium were reduced in length 
and flattened in acute (pure) pregnancy toxemia, and the shortening of microvilli was further advanced in specimens with mixed toxemia.

2. The endoplasmic reticulum of syncytial epithelium with acute (pure) pregnancy toxemia was swollen and vacuolated, and in specimens with mixed pregnancy toxemia the swelling and the vacuolation were more intensified.

3. A little variation is found in the nucleus, mitochondria, etc. of the syncytial epithelium.

\section{References}

1) Schmorl, G.,: Zur Lehre von der Eklampsie, Arch. Gynäk., 65, 504 (1902).

2) Tenney, B., and Parker, F.,: The placenta in toxemia of pregnancy, Am. J. Obst. Gynec., 39, 1000 (1940).

3) Stroganova, U.,: Die placentare Theorie in der Pathogenese der Schwangerschaftstoxikosen, im speziellen der Eklampsie, Arch. Gynäk., 160, 431 (1936).

4) Watanabe, Y.,: The pathological studies of the human placenta, J. Jap. Obst. Gynec. Society, 7, 619 (1955).

5) Namiki, K.,: Histopathological studies on the human placenta with special attention of Vines- and PAS-staining, Tohoku Igaku Zassi, 53, 129 (1956).

6) Takeyama, T.,: Electron microscopic study on the human chorionic villi, Osaka Daigaku Igaku Zassi, 10 (6), suppl., 1707 (1958).

7) Watanabe, Y.,: Intra-cytoplasmic sac or cytoplasmic filamentous structure of cells, Saibo-kagaku Symposium, 5, 35 (1957).

8) Palade, G. E., and Porter, K. R.,: Studies on the endoplasmic reticulum. 1. Its identification in cells in situ, J. Exp. Med., 100, 641 (1954).

9) Palade, G. E.,: Studies on the endoplasmic reticulum. 11. Simple disposition in cells in situ, J. Biophys. Biochem. Cytol., 1, 567 (1955).

10) Palade, G. E.,: The endoplasmic reticulum, J. Biophys. Biochem. Cytol., 2 (suppl.), 85 (1956).

11) Takagi, F., et al.: Electron microscopic cytohistopathology (1), Studies on autolytic changes of ultra-cell structures, Jikeikai Med. J., 2, 21 (1955).

12) Sjöstrand, F. S.,: Electron microscopy of cells and tissues, Physical Techniques in Biological Research, Academic Press Inc., N. Y., 3, 20 (1956). 